\title{
Use of carbon and aluminosilicate nanofillers in XNBR composites designed for protective materials against oils
}

\author{
Sylwia M. Krzemińska ${ }^{1 *}$, Aleksandra A. Smejda-Krzewicka ${ }^{2}$, Andrzej Leniart ${ }^{3}$ \\ ${ }^{1}$ Central Institute for Labour Protection - National Research Institute, Department of Personal Protective Equipment, \\ Wierzbowa 48, 90-133 Lodz, Poland \\ ${ }^{2}$ Lodz University of Technology, Institute of Polymer and Dye Technology, Stefanowskiego 12/16, 90-924 Lodz, Poland \\ ${ }^{3}$ University of Lodz, Faculty of Chemistry, Department of Inorganic and Analytical Chemistry, Tamka 12, 91-403 Lodz, \\ Poland \\ "Corresponding author: e-mail: sykrz@ciop.lodz.pl
}

\begin{abstract}
The objective of the work was to investigate the possibility of application of carbon and bentonite nanoparticles in carboxylated acrylonitrile-butadiene rubber (XNBR) and the related effects of the nanofillers on the structure, as well as mechanical and barrier properties, of the resulting composites. The composites were designed for use in protective clothing and gloves. XNBR compounds were modified with $2 \mathrm{phr}$ of graphene flakes, graphene oxide, or modified bentonite, and crosslinked with sulfur-accelerator system. Rubber compounds were prepared using a conventional method with a laboratory rolling mill. The composites were studied in terms of structure (WAXS), surface morphology (AFM), the presence of functional groups (ATR-FTIR) barrier properties against chemical substances (mineral oil) and swelling properties, as well as mechanical properties (abrasion resistance and tensile strength). The composites were characterized by very high resistance to oil permeation (breakthrough time $>480 \mathrm{~min}$ ). The type of nanofiller added to the XNBR blend in the amount of $2 \mathrm{phr}$ did not significantly affect mechanical parameters.
\end{abstract}

Keywords: carboxylated nitrile butadiene rubber; XNBR composites; graphene; graphene oxide; bentonite.

\section{INTRODUCTION}

Over the years, increasing attention has been given to polymeric materials containing various nanoparticles, such as aluminosilicate nanofillers ${ }^{1}$ (including montmorillonite and bentonite) and, more recently, carbon nanofillers, especially graphene and graphene oxide. Those nanoparticles have been added to polymeric compounds to improve their properties, ${ }^{2}$. The reinforcing ability of nanofillers depends on the particle size, structure, surface characteristics, and degree of dispersion ${ }^{4}$. Polymer nanocomposites are attractive because of substantially improved mechanical, electrical properties, flame and heat resistance and barrier properties, ${ }^{2,4}$. Polymer-clay nanocomposites containing layered silicates are the most promising. The platelet structure of layered silicates plays a crucial role in increasing the barrier properties of polymeric materials due to the tortuous path model ${ }^{4}$. The small particle size $(1-100 \mathrm{~nm})$, high specific surface area, and high surface area-to-volume ratio of nanofillers change the reactivity and physical properties of the elastomers without affecting their bulk properties, such as density ${ }^{5}$. Based on the number of dimensions in the nanometer scale, nanofillers are classified into three groups:

- one-dimensional, e.g., plates, laminas, layered silicates;

- two-dimensional, e.g., nanotubes, nanofibers;

- three-dimensional, e.g., nanogranules, nanocrystals, nanosilica.

Among nanofillers, layered silicates are the most widely used in commercial applications. Numerous studies have explored the incorporation of nanoclays into natural rubber, styrene-butadiene rubber, ethylene-propylene-diene rubber, epoxidized natural rubber, and, to a lesser extent, other rubbers ${ }^{5}$. In addition, graphene sheets can also provide effective reinforcement to elastomers. In graphene, the sp2-hybridized carbons are arranged in a honeycomb structure offering a large surface area. Graphenes have the unique capacity of enhancing thermal, electrical, and barrier properties ${ }^{5,6}$. Graphite and graphene oxide (GO) have emerged as new layered carbon particles with nano size effects and unique features ${ }^{7}$. Graphene oxide is a material that can replace other rubber-improving fillers. $\mathrm{Mao}^{7}$ emphasized that for successful application of GO in the rubber industries commodity rubbers should be selected as matrixes and the fabrication method should be environmentally friendly. The latest studies are focused on the electric, thermal, mechanical, and some other functional properties of rubber composites with GO.

The content of nanofillers in the compounds amounts to $3-12 \mathrm{phr}$ for layered aluminosilicates and $1-3 \mathrm{phr}$ for graphene and graphene oxide ${ }^{8-10}$, which constitutes a significant difference as compared to the conventional fillers, such as carbon black, silica and others, with a content of 20-25 phr. This also represents a major improvement due to the fact that high filler concentrations are technologically unfavorable and increase product weight.

Polymeric composites with graphene particles are used increasingly often as a result of their superior mechanical, thermal, electrical, and barrier properties ${ }^{11}$. In order to reduce costs, extensive research efforts are under way to obtain hybrid composites containing graphene in conjunction with other kinds of particles. These include layered aluminosilicates, so-called nanoclays, or other types of carbon nanofillers (nanotubes). Graphene and aluminosilicates improve tensile strength and resistance to permeation by chemical substances. Hence, it is expected that in hybrid composites those properties will be even more pronounced than in the rubber compounds containing only aluminosilicate particles manufactured to date. This prediction is associated with the similarity of the layered structures of graphene and aluminosilicates, with 
the former consisting of much smaller sheets, enhancing their dispersion in the polymeric matrix.

Nanofillers in composites are also used to enhance barrier properties, both against gases and liquids. In terms of personal protective equipment (PPE) the protective characteristics of materials are determined in the laboratory on the basis of breakthrough time by a given chemical. Breakthrough time is defined as the time elapsed from the moment the tested material sample makes contact with a given chemical substance to the moment a set amount of that substance emerges on the other side of the sample. Since permeation resistance testing of polymeric composites is time-consuming and costly, efforts are under way to develop theoretical models and tools facilitating its preliminary estimation.

One of the methods allowing qualitative assessment of the solubility of chemicals in polymer-chemical systems utilizes the solubility parameters $\delta$ of the polymer and the chemical substance, which reflects their thermodynamic affinity under equilibrium conditions. The solubility parameter is defined as the square root of molar cohesion energy, which is the energy necessary to overcome intermolecular interaction forces, per unit of volume ${ }^{12}$.

According to Hildebrand's theory of regular solutions $^{13}$, two substances characterized by similar solubility parameters should be soluble in each other, which is consistent with the general principle that the chemical and structural similarity of substances favors their solubility. It is assumed that if the absolute difference of the solubility parameters of the polymer and the solvent is low $\left(\mid<1.0 \mathrm{MPa}^{0.5}\right)$ the former dissolves well in the latter. As this difference increases, solubility gradually declines to the gradient threshold value $\left(>2.4 \mathrm{MPa}^{0.5}\right)$, at which solubility becomes negligible.

The objective of the work was to investigate the possibility of application of carbon and bentonite nanoparticles in carboxylated acrylonitrile-butadiene rubber (XNBR). This study is focused on identifying the effects of different types of nanofillers on the structure, mechanical and barrier properties of composites designed for use in personal protective equipment, including safety clothing and gloves. Characterization of nanocomposites was carried out by WAXS, AFM, and IR analysis.

\section{EXPERIMENTAL}

\section{Material}

The studied material was crosslinked carboxylated acrylonitrile-butadiene rubber (XNBR) either without a nanofiller (XNBR No Filler) or containing 2.0 phr of:

- graphene flakes (XNBR Graphene) or
- graphene oxide (XNBR-GO) or

- layered aluminosilicate (bentonite, XNBR Bentonite). XNBR No Filler is the reference sample.

The samples were made using Krynac X 750 rubber (27\% bound acrylonitrile, $7 \%$ bound carboxylic acid, density $0.99 \mathrm{~g} / \mathrm{cm}^{3}$, Mooney viscosity [ML $\left.(1+4) 100^{\circ} \mathrm{C}\right]$ $47 \pm 5)$ manufactured by Lanxess $\mathrm{GmbH}$ (Germany). Among the various possible methods of XNBR crosslinking, involving sulfur ${ }^{14}$, microsized zinc oxide of different shapes (whiskers, snowflakes, spherical particles) ${ }^{\mathbf{1 5}}$ and a crosslinking system composed of both zinc oxide and sulfur $^{\mathbf{1 6}}$, sulfur alone for the present study. In this study, XNBR was crosslinked only with sulfur (article number 527795704, content: $99.85 \%$, bulk density $400-500 \mathrm{~kg} / \mathrm{m}^{3}$ ) from Chempur (Poland) in the presence of accelerator and stearic acid.

Dispersant: stearic acid (trade name Tefacid RG, acid value 194-210, iodine value $\leq 8$, carbon chain $\mathrm{C}_{18}$ : 50-70\%) manufactured by AarhusKarlshamn (Sweden).

Accelerator: zinc diethyldithiocarbamate (trade name LUVOMAXX ZDEC, density: $1.480 \mathrm{~g} / \mathrm{cm}^{3}$ at $20^{\circ} \mathrm{C}$, bulk density: $330-370 \mathrm{~kg} / \mathrm{m}^{3}$, practically insoluble in water) manufactured by Lehmann \& Voss \& Co.KG (Germany).

Antioxidant: 2,2'-methylene-bis[(6-(1-methylcyclohexyl)]-p-cresol (trade name LOWINOX WSP, water solubility: $<0.01 \mathrm{~g} / \mathrm{dm}^{3}$ ) purchased from Enkev Polska Sp. z o.o (produced by BASF, Germany).

Nanofiller: bentonite, a layered aluminosilicate modified with quaternary ammonium salts $\left(\mathrm{R}_{1} \mathrm{R}_{2} \mathrm{R}_{3} \mathrm{R}_{4} \mathrm{~N}^{(+)}\right.$ $\left.\mathrm{Cl}^{(-)}\right)$, where $\mathrm{R}_{1}=3$-chloro-2-hydroxypropyl substituent, $\mathrm{R}_{2}, \mathrm{R}_{3}$, and $\mathrm{R}_{4}=$ methyl substituents, manufactured by and obtained from ZGM Zębiec S.A., Poland.

Nanofiller: graphene flakes prepared from expandable natural graphite (large flakes, 95\% >180 $\mu \mathrm{m}$ [+180 mesh], including $60 \%>300 \mu \mathrm{m}$ [+50 mesh]) was manufactured by and obtained from the Institute of Electronic Materials Technology, Poland.

Nanofiller: graphene oxide (GO) prepared from expandable natural graphite (large flakes, 95\% >180 $\mu \mathrm{m}[+180 \mathrm{mesh}]$, including $60 \%>300 \mu \mathrm{m}[+50 \mathrm{mesh}])$ was manufactured by and obtained from the Institute of Electronic Materials Technology, Poland. Graphene oxide was prepared using the modified Hummer method developed by the same Institute.

All the chemical reagents used were of analytical grade.

The formulations of rubber composites are presented in Table 1.

\section{Preparation of samples}

Rubber compounds were prepared by the conventional method using a laboratory two roll mill with 100x200 mm rolls, at a rolls temperature of $20-25^{\circ} \mathrm{C}$ and friction of

Table 1. Formulations of XNBR composites ( $\mathrm{phr}^{\mathrm{a})}$ )

\begin{tabular}{|c|c|c|c|c|}
\hline Ingredient & $\begin{array}{c}\text { XNBR } \\
\text { No filler }\end{array}$ & XNBR Graphene & $\begin{array}{c}\text { XNBR } \\
\text { GO }\end{array}$ & $\begin{array}{c}\text { XNBR } \\
\text { Bentonite }\end{array}$ \\
\hline XNBR & 100 & 100 & 100 & 100 \\
\hline Carbon black (sulfur) & 1.2 & 1.2 & 1.2 & 1.2 \\
\hline Stearic acid & 2.0 & 2.0 & 2.0 & 2.0 \\
\hline Zinc diethyldithiocarbamate & 1.1 & 1.1 & 1.1 & 1.1 \\
\hline 2,2'-Methylenebis[(6-(1-methylcyclohexyl)]-p-cresol & 0.6 & 0.6 & 0.6 & 0.6 \\
\hline Graphene flakes & - & 2.0 & - & - \\
\hline Graphene oxide & - & - & 2.0 & - \\
\hline Modified bentonite & - & - & - & 2.0 \\
\hline
\end{tabular}

a) Parts per hundred rubber 
1:1.1. Mixing was conducted for up to 10-11 min, until all the components were thoroughly mixed. The compounds were stored at ambient temperature. The mixing procedure was as follows: step 1 - preparation of the premix solution $(\mathrm{XNBR}+$ dispersant + accelerator + antioxidant), $6 \mathrm{~min}$ and division of the premix solution into several parts (sulfur was added to one part immediately - reference composite); step 2 - introduction of fillers, 3 min; step 3 - introduction of sulfur, 1 min; step 4 - homogenization of the mixture, $1 \mathrm{~min}$.

In order to ensure optimum crosslinking conditions (time and temperature) vulcametric measurements were conducted according to the standard PN-ISO 3417:1994, using a WG-02 oscillating disc vulcameter with a disc amplitude of $\pm 3^{\circ}$ and oscillation frequency of $1.7 \pm 0.1$ $\mathrm{Hz}$. Rheological properties of XNBR composites are given in Table 2.

Table 2. Rheometric properties of XNBR composites

\begin{tabular}{|l|c|c|c|c|}
\hline Composite & $\mathrm{L}_{\min }, \mathrm{dNm}$ & $\Delta \mathrm{L}, \mathrm{dNm}$ & $\tau_{02}, \min$ & $\tau_{90}, \mathrm{~min}$ \\
\hline XNBR No filler & 12.9 & 30.4 & 2.93 & 32.68 \\
\hline XNBR GO & 19.3 & 22.7 & 3.60 & 44.18 \\
\hline XNBR Bentonite & 20.7 & 29.3 & 2.53 & 38.17 \\
\hline
\end{tabular}

note: $\mathrm{L}_{\min }-$ minimal torque, $\Delta \mathrm{L}$ - torque increment, $\tau_{02}-$ scorch time, $\tau_{90}$-cure time

Composite samples were produced in steel molds with a diameter of 80 or $150 \mathrm{~mm}$. The molds containing crude XNBR compounds were placed between electrically heated $\left(140^{\circ} \mathrm{C}\right)$ platens of a hydraulic press, between two Teflon sheets; the heating time was $30 \mathrm{~min}$. Subsequently, the samples were allowed to stand for 24 $\mathrm{h}$ and then removed from the dies. The width variation of the samples was $0.43-0.60 \mathrm{~mm}$.

\section{Test method}

\section{Wide-angle X-ray scattering (WAXS)}

WAXS was used to study the nature of nanofiller dispersion in composites. WAXS was done with an URD 63 (Seifert, Germany) diffractometer using $\mathrm{CuK}_{\alpha}$ radiation and the following settings: accelerating voltage $-40 \mathrm{kV}$, anodic current - $30 \mathrm{~mA}$. Radiation was monochromatized with a nickel filter and impulse height discriminator. A scintillation counter was used as a detector. X-ray diffractograms of the composite materials were made by the stepwise method within a diffraction angle range of $3-60^{\circ}$, with a step of $0.1^{\circ}$. The impulse counting time was $15 \mathrm{~s}$ in all cases.

\section{Atomic force microscopy (AFM)}

AFM studies were made with the Bruker Dimension Icon Atomic Force Microscope (Santa Barbara, CA USA). AFM images were taken in the tapping mode using a silicon probe (model TESPA-V2, Bruker) with a rectangular cantilever with a nominal spring constant

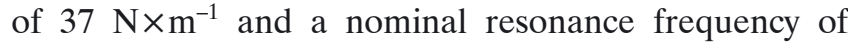
$320 \mathrm{kHz}$. Scanning was carried out at two randomly chosen places for each sample, simultaneously recording height (topography), phase, and amplitude images. The scan area was $1 \mu \mathrm{m} \times 1 \mu \mathrm{m}$. Before the measurement, samples of composites were rinsed with $95 \%$ analytical grade ethanol (POCh SA, Gliwice, Poland) and dried with argon (5 N, Linde Gaz, Lodz, Poland).

\section{Infrared spectroscopy ATR-FTIR}

The XNBR vulcanizates were characterized by Attenuated Total Reflectance Fourier Transform Infrared spectroscopy (ATR-FTIR). The spectra were recorded within the wavelength range between 3500 and $600 \mathrm{~cm}^{-1}$ using FTIR $175 \mathrm{C}$ (Bio Rad).

\section{Testing of mechanical properties}

The selected mechanical properties of the composites, that is, tensile strength at break and abrasion resistance were investigated in accordance with the Standard EN 388:2003.

Tensile tests were conducted on a universal testing machine (type 1435, Zwick GmbH \& Co. KG, Germany) with a crosshead speed of $500 \mathrm{~mm} / \mathrm{min}$ according to BS ISO 37:2005. The results are expressed as means for 5 samples.

Abrasion resistance was measured on 4 samples using a standard tester (Nu-Martindale, James H. Heal Ltd., Great Britain). The pressure exerted on the samples during abrasion was $9 \pm 0.2 \mathrm{kPa}$. Prior to the tests, the samples were conditioned in air at $21 \pm 3^{\circ} \mathrm{C}$ and a relative humidity of $50 \pm 5 \%$.

\section{Testing of barrier properties}

The testing of barrier properties (resistance of the studied materials to permeation by the selected mineral oil) was conducted pursuant to the standard EN 374-3:2003 "Protective gloves against chemicals and micro-organisms. Part 3: Determination of resistance to permeation by chemicals". According to the standard, permeation resistance is expressed as breakthrough time, or the time elapsed from the moment the material makes contact with a given chemical substance to the moment the permeation rate of the substance has reached $1 \mu \mathrm{g} /$ $\mathrm{cm}^{2} \times$ min. This testing method was presented by the Authors in a prior publication ${ }^{17}$.

According this test, a sample of the examined material was fixed between the two chambers of a permeation cell. The external surface of the material contacted with mineral oil, while the internal surface made contact with a solid absorbent medium, that is, GF/A and GF/C Whatman glass microfiber filters. Subsequently, 10 $\mathrm{mL}$ of mineral oil was poured into the upper chamber of the permeation cell and timing was started. Interval measurements were conducted, which means that at certain points in time $(10,30,60,120,240$ and $480 \mathrm{~min}$ since the start) the filters were taken for analysis. These intervals corresponded to the protection levels given in the standard EN 374-1:2003. Quantitative analysis was made using gas chromatography with a flame-ionization detector $^{18}$. A Trace GC gas chromatograph (Unicam) equipped with a flame-ionization detector (FID) and a capillary chromatographic column (Rtx-5, length $30 \mathrm{~m}$, internal diameter $0.25 \mathrm{~mm}$ ) were used. Oil determination was conducted in accordance with the standard EN ISO 9377-2:2000 "Water quality. Determination of hydrocarbon oil index: Part 2. Method using solvent extraction and gas chromatography". The test lasted $480 \mathrm{~min}$.

\section{Resistance to swelling}

The swelling test was conducted by immersing for $72 \mathrm{~h}$ the material samples into solvent: hexane. The samples 
were weighed before immersion and after immersion. Next, the samples were dried at $40^{\circ} \mathrm{C}$ for $24 \mathrm{~h}$ and then weighed. The procedure was analogous to that used in our previous work ${ }^{19}$.

For one type of composite - XNBR material without the filler, the Mooney-Rivlin elasticity constants were determined using the standard technique, according to the protocol applied in our previous studies ${ }^{\mathbf{2 0}, \mathbf{2 1}}$.

\section{Statistical Analysis}

The test results for mechanical parameters were statistically analyzed using STATISTICA software.

Normality of distribution was analyzed using the Szapiro-Wilk test, and homogeneity of variances for the studied sample types was analyzed with the Levene test.

In the case of normal distribution (tensile strength at break), statistical significance analysis involved one-way ANOVA and the post-hoc Tukey test for pairwise comparisons.

In the case of a non-normal distribution (abrasion resistance results), statistical significance was analyzed with the non-parametric Kruskal-Wallis test with correction for tied ranks and the post-hoc Dunn-Bonferroni test.

Statistical significance was adopted at $\mathrm{p}<0.05$.

\section{RESULTS AND DISCUSSION}

\section{Examination of nanomaterial structure}

The results of WAXS studies of XNBR composites are given in Table 3. As can be seen, the use of the same amount of different nanofillers produced different effects. Only in the case of one composite, XNBR Bentonite, the WAXS curve showed one peak at $1.38 \mathrm{~nm}$. It is interesting to note that the interlayer distance was below the initial value of bentonite at $1.8 \mathrm{~nm}\left(2 \theta=4.93^{\circ}\right)$. The observed decrease in interlayer distance resulted in larger or smaller agglomerations rather than individual bentonite layers in the studied composite samples, which was deemed an adverse phenomenon, leading to reduced strength parameters.

Table 3. XRD results

\begin{tabular}{|c|c|c|c|}
\hline Composite & $\begin{array}{c}\text { Concentration } \\
\text { of filler, phr }\end{array}$ & $\begin{array}{c}\text { Interlayer } \\
\text { distance }^{\mathrm{a})}, \mathrm{nm}\end{array}$ & Angle $2 \theta$ \\
\hline $\begin{array}{l}\text { XNBR } \\
\text { Graphene }\end{array}$ & 2.0 & 0.33 & 26.60 \\
\hline XNBR GO & 2.0 & No peak & - \\
\hline $\begin{array}{l}\text { XNBR } \\
\text { Bentonite }\end{array}$ & 2.0 & 1.38 & 6.40 \\
\hline
\end{tabular}

a) Interlayer distance was computed using the Bragg formula

In the case of the XNBR composite with graphene (XNBR Graphene), the WAXS revealed a peak of $2 \mathrm{q} \approx 26^{\circ}$ (Fig. 1), which is consistent with literature data as WAXS curves for graphene (graphite) are characterized by a strong single maximum at an angle of $2 q \approx 26^{\circ}{ }^{16,17}$. In the XNBR Graphene sample, there were larger or smaller agglomerates rather than individual graphene layers.

In contrast, the WAXS curves for XNBR GO samples did not show a peak at characteristic wavelengths (Fig. 1), so it was impossible to determine the distance between nanofiller layers. Thus, it may be assumed that graphene oxide layers underwent exfoliation, which is consistent with the absence of WAXS peaks (and in particular the one at $\left.2 q \approx 10.6^{\circ}\right)^{22,23}$. Such a structure may affect the properties of the resulting nanocomposites, as confirmed by, e.g., Aina and Azura ${ }^{24}$, who reported that nanofiller type (silica, mica, carbon black, calcium carbonate) and quantity (10-20 phr) applied in XNBR latex exerts an effect on the morphology and mechanical properties of the resulting composites. However, at that degree of filling

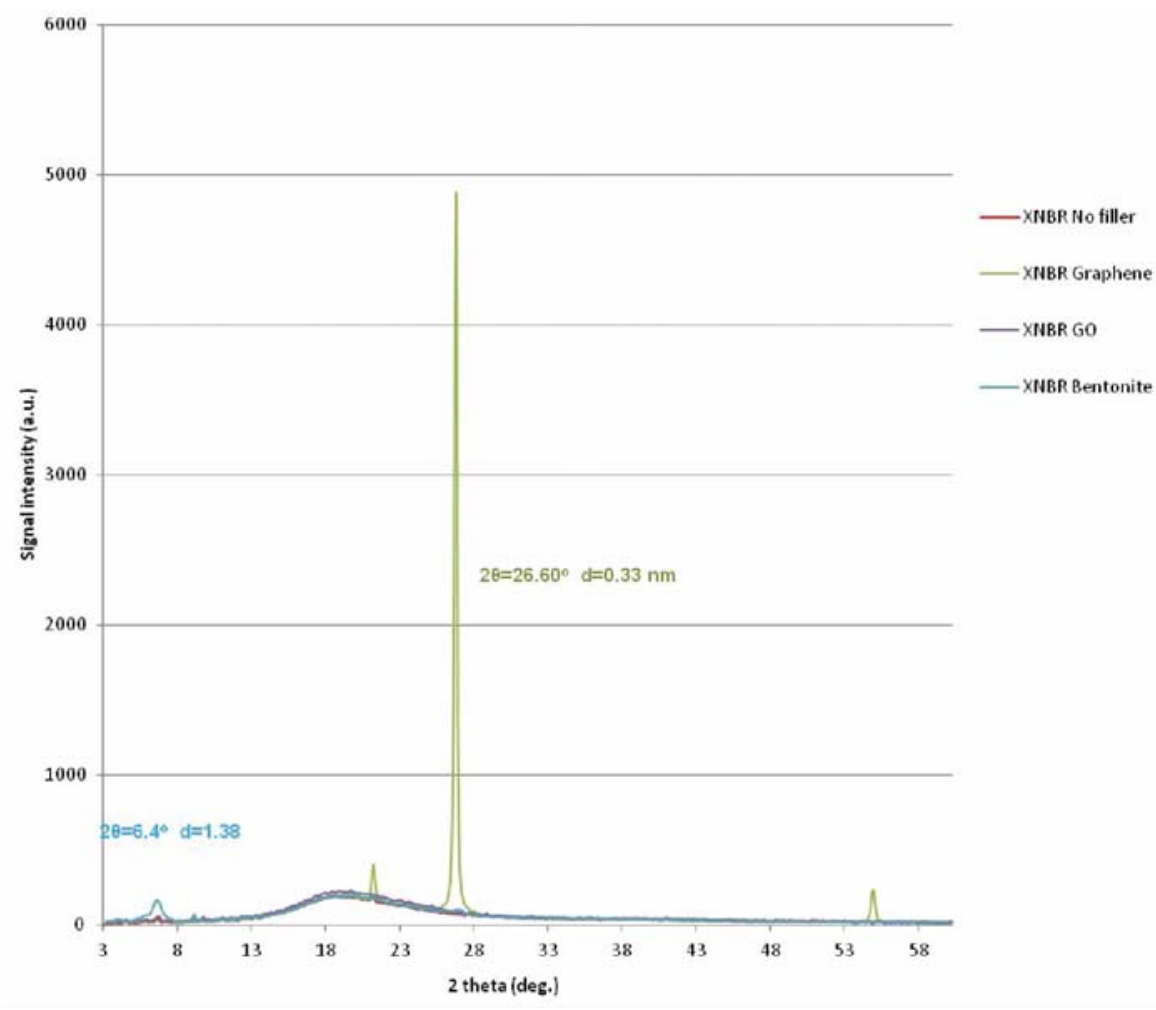

Figure 1. WAXS curve for XNBR composite without nanofiller, with 2 phr of graphene (XNBR Graphene), graphene oxide (XNBR Graphene oxide) or bentonite (XNBR Bentonite) 
it was difficult to obtain appropriate filler dispersion in the latex and XNBR matrix.

The objective of the present study, involving the application of one amount of nanofillers only, prevents elucidation of the effects of nanofiller concentration on interlayer distance. Research in this area, concerning organoclays and natural rubber (NR), was conducted by George et al. ${ }^{25}$, who used 1, 3, 5, 10 and $15 \mathrm{phr}$ of the Closite aluminosilicate nanofiller, which has similar properties to the bentonite nanofiller used in this study. In the work of Thomas, interlayer distance generally increased with clay content. At lower clay concentrations, such as 1 and $3 \mathrm{phr}$, there was no significant change in the X-ray diffraction spectrum. The concentration of 5 phr of clay was optimum for improvement of composite properties and intercalation. The interlayer distance for this clay amount was $2.60 \mathrm{~nm}$, which was higher than the initial value for clay $(2.32 \mathrm{~nm})$. Therefore, it may be assumed that the application of bentonite at amounts lower than $5 \mathrm{phr}$ in this work led to insufficient dispersion. On the other hand, the composite with bentonite was used as a reference sample for composites containing graphene and graphene oxide, which are introduced to polymer composites in lower amounts.

\section{Surface morphology studies of composites}

Figure 2a-d presents AFM images of the surface of the investigated samples (XNBR No filler, XNBR Graphene, XNBR GO and XNBR Bentonite). The AFM image of XNBR No filler (Fig. 2a) demonstrates a homogeneous surface structure without the addition of any fillers. In the case of XNBR Graphene, the image (Fig. 2b) clearly shows structures corresponding to graphene flakes. This indicates that graphene flakes are arranged in parallel to each other, one on top of another, in the outer layers of this composite. In XNBR GO (Fig. 2c), the surface structure contains irregularly shaped elements that are most probably associated with graphene oxide flakes. The AFM image shows that graphene oxide flakes in XNBR GO are distributed irregularly. The AFM image of XNBR Bentonite (Fig. 2d) clearly indicates that bentonite particles are agglomerated in larger structures.

In addition, the root mean square average of height deviations from the mean image data plane $(\mathrm{Rq})$, the arithmetic average of the absolute values of surface height deviations measured from the mean plane (Ra) (a)

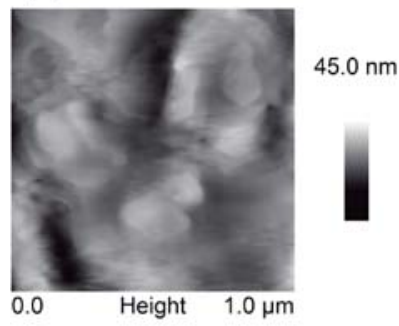

(b)

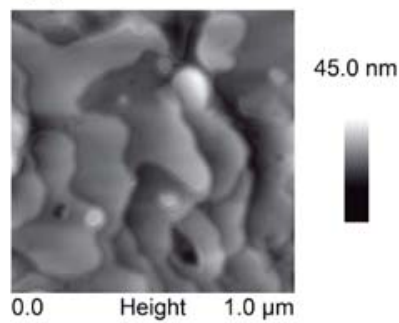

(c)

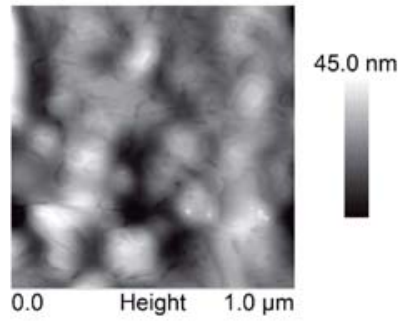

(d)

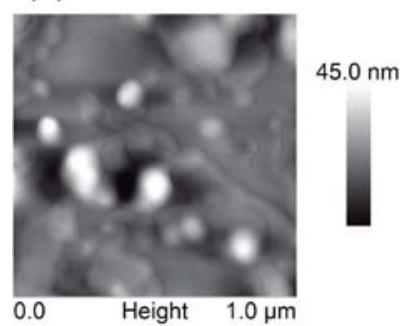

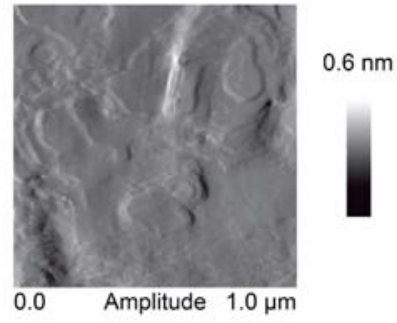
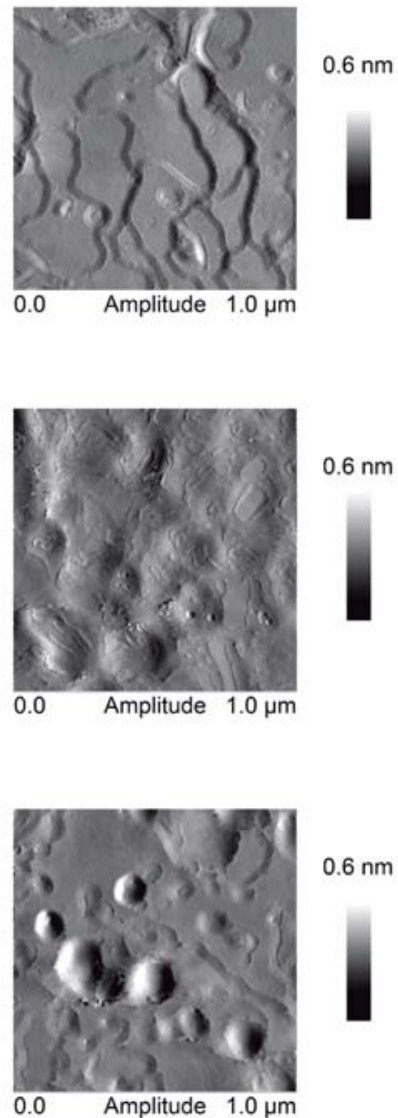

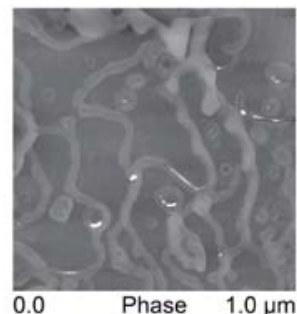

$40.0^{\circ}$

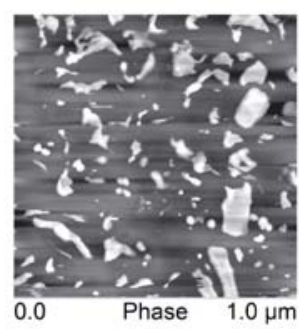

$40.0^{\circ}$

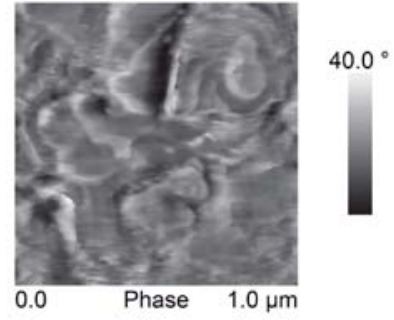

0.0
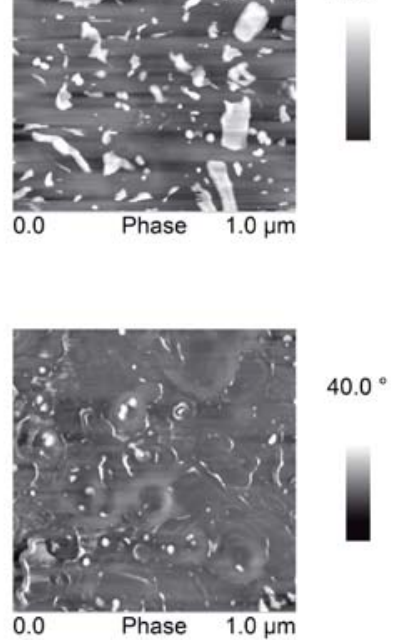

Figure 2. AFM images of XNBR No filler (a), XNBR Graphene (b), XNBR GO (c) and XNBR Bentonite (d) 
and surface area difference (SAD) were determined using the Bruker Nanoscope Analysis software (version 1.4). The surface parameter values from roughness analysis are presented in Table 4. As can be seen, the addition of nanofillers to XNBR caused an increase in those parameters. The highest values were obtained for XNBR Bentonite.

Table 4. The surface parameters values from the roughness analysis

\begin{tabular}{|l|c|c|c|}
\hline Composite & $\mathrm{Rq}[\mathrm{nm}]$ & $\mathrm{Ra}[\mathrm{nm}]$ & SAD [\%] \\
\hline XNBR No filler & 26.3 & 18.5 & 2.58 \\
\hline XNBR Graphene & 71.8 & 49.2 & 6.44 \\
\hline XNBR GO & 34.0 & 23.7 & 6.66 \\
\hline XNBR Bentonite & 163.0 & 74.3 & 11.40 \\
\hline
\end{tabular}

The WAXS and AFM results correlated with each other for graphene oxide and bentonite. In the case of graphene oxide, WAXS showed exfoliation of graphene oxide after its introduction into the matrix, while AFM confirmed the existence of individual flakes. In the case of bentonite, WAXS indicated a reduction in the distance between bentonite as powder and bentonite in composites, as well as increased agglomeration, as confirmed by AFM imaging.

Figure 3 show the ATR spectra of the XNBR composite without nanofiller and with nanofiller. Each spectra shows the existence of two main absorption peaks for the XNBR compounds at about $2920 \mathrm{~cm}^{-1}$ and 2848 $\mathrm{cm}^{-1}$ due to the presence of the $-\mathrm{CH}_{2}$ groups ${ }^{26}$. Another absorption peak at $2237 \mathrm{~cm}^{-1}$ is due to the $\mathrm{CN}$ - group in the acrylonitrile component. The important region of spectrum is the range from 1697 to $808 \mathrm{~cm}^{-1}$. In this region peaks result from the $>\mathrm{C}=\mathrm{O}$ group of the carboxylic component in XNBR. The peak for $-\mathrm{COOH}$ appears at wavelength of $1697 \mathrm{~cm}^{-1}$. Introduction of nanofillers did not change the ATR spectra in any significant way.

\section{Rheometric studies}

The torque increment DL (Table 2) decreased slightly for XNBR composites with nanofillers. It is known from the literature that an increase in torque increment reflects crosslinking density, which in turn influences the mechanical properties of composites ${ }^{26}$. An increased torque increment is necessary to improve tensile strength at break and stress at elongation. The observed reduction in the torque increment of XNBR composites with graphene oxide and bentonite may have translated into not very good mechanical properties (Fig. 4-5).

The effect of nanofiller type on the mechanical properties of materials

The test results for the investigated mechanical properties of XNBR materials are presented in Figs. 4-6.

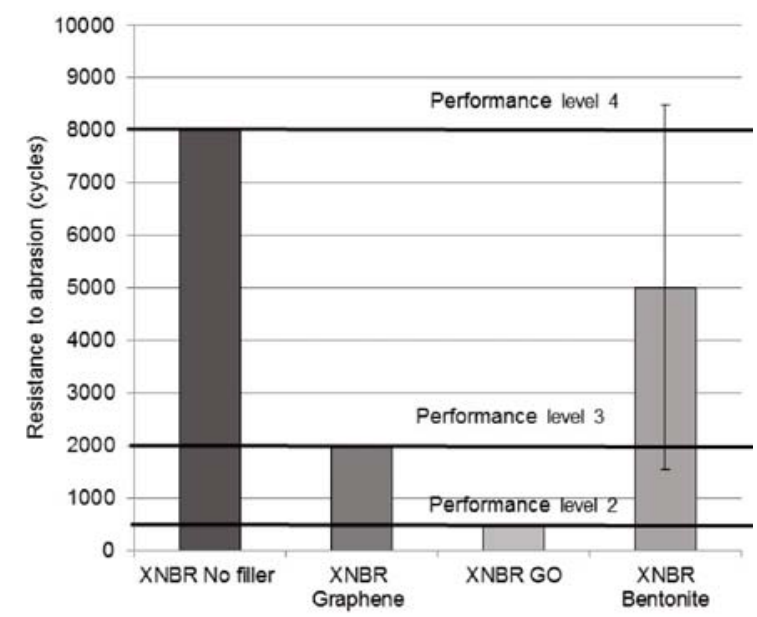

Figure 4. Abrasion resistance for XNBR composites

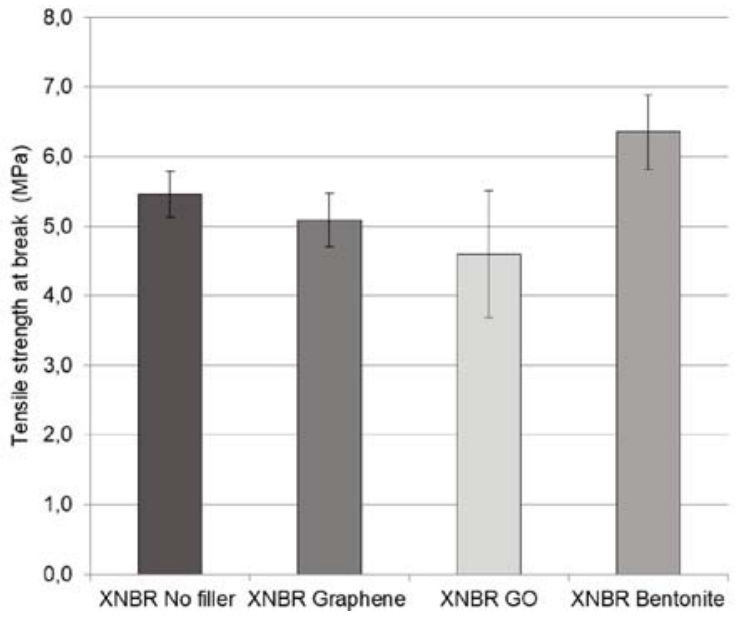

Figure 5. Tensile strength at break for XNBR composites

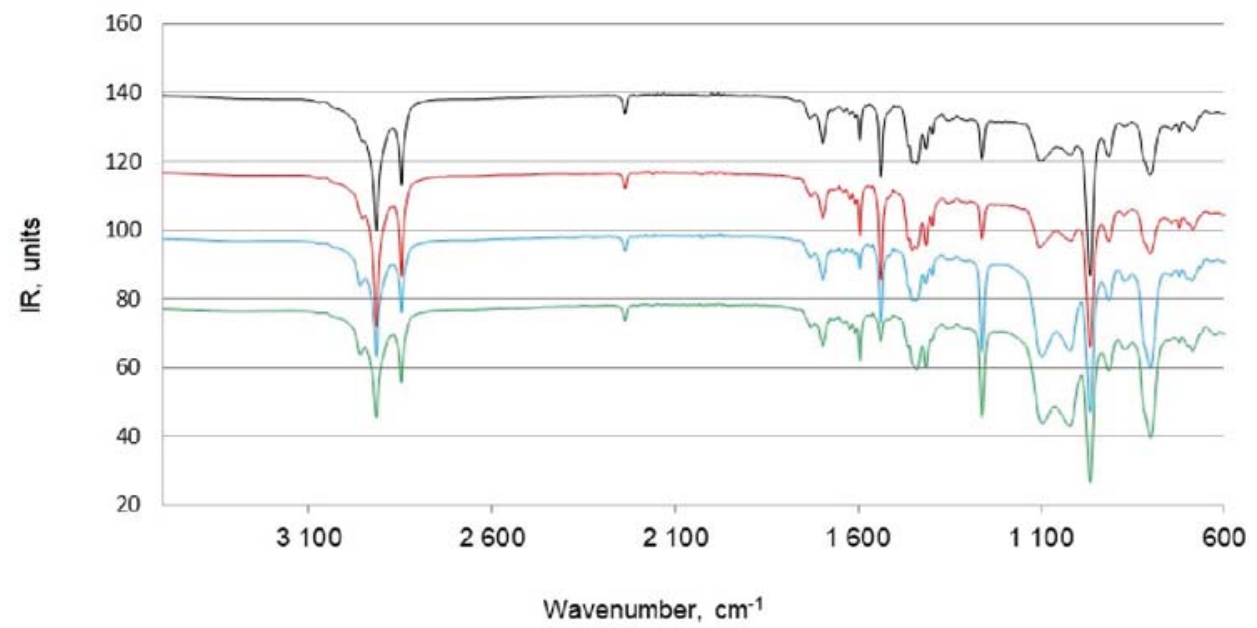

Figure 3. ATR spectra of XNBR composite without and with different nanofillers 


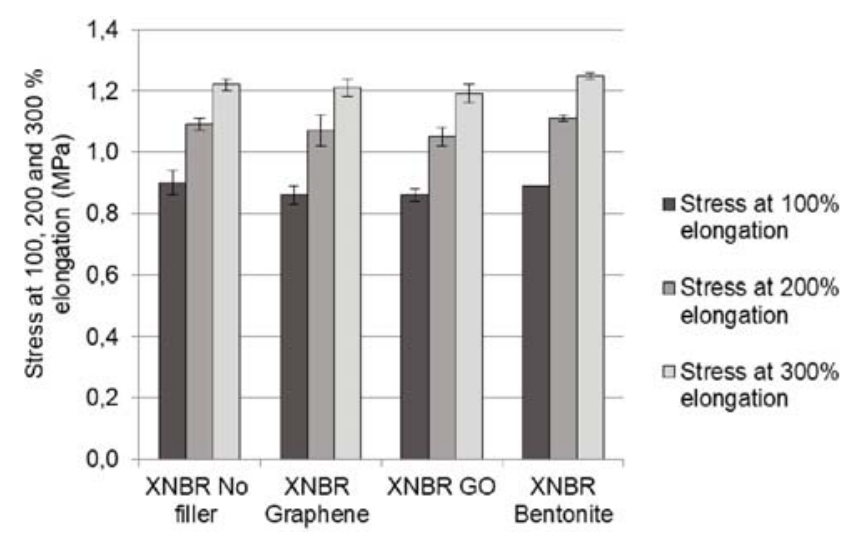

Figure 6. Tensile stress at 100, 200, and 300\% elongation for XNBR composites

Contrary to expectations, the addition to the XNBR of a carbon nanofiller (graphene flakes or graphene oxide) or an aluminosilicate nanofiller (modified bentonite), did not significantly improve the mechanical properties of the vulcanizates. Irrespective of the type of nanofiller added in the quantity of $2 \mathrm{phr}$, abrasion resistance expressed as the number of cycles to failure decreased (Fig. 4). The reference sample (XNBR No Filler) exhibited high abrasion resistance (8000 cycles, corresponding to the highest, 4th protection class) as compared to nanofiller-containing XNBR composites. Indeed, the abrasion resistance of XNBR GO was 500 cycles (2nd protection class), that of XNBR Graphene was 2000 cycles (3rd class), and that of XNBR Bentonite was 5000 cycles (3rd class). Statistical analysis showed that the addition of nanofillers (irrespective of their type) significantly deteriorated the parameter in question $(p=0.05$ or $p=0.01$, depending on the variant).

In turn, nanofillers did not affect tensile strength at break (Fig. 5), which was 5.46 MPa for the reference sample (XNBR No Filler) and 4.6-6.4 MPa for the nanofiller-containing composites. Although the highest tensile strength at break was observed for XNBR Bentonite (6.35 MPa), statistical analysis revealed that the type of nanofiller added to the XNBR blend in the amount of $2 \mathrm{phr}$ did not significantly affect this parameter (with $p$ ranging from 0.233 to 0.979 ). Furthermore, the stress of the composite increased for increasing modulus at $100 \%, 200 \%$ and $300 \%$ elongation. However, the stress determined at 100, 200, and 300\% elongation did not differ significantly $(\mathrm{p}>0.05)$ between the various composites (Fig. 6).

In light of the literature data ${ }^{10}$, it was observed that the mechanical properties of XNBR crosslinked with sulfur in this study were not as good as for XNBR crosslinked with zinc oxide particles of different shapes (whiskers, snowflakes, spheres) and different specific surface areas. For XNBR crosslinked with sulfur, the obtained tensile strength was approx. $6.5 \mathrm{MPa}$. In other studies with zinc oxide crosslinking at 3 to $8 \mathrm{phr}$, the vulcanizates were characterized by excellent mechanical properties (tensile strength up to $38.2 \mathrm{MPa}$ for snowflakes). Good results were also obtained for XNBR blends crosslinked with both zinc oxide and sulfur at $5.0 \mathrm{phr}$ and $2.5 \mathrm{phr}$, respectively ${ }^{16}$. The filler of the blend was keratin from the process of cattle hide unhairing. The above vulcanizates were characterized by increased tensile strength (14.4
MPa). Other studies used not only graphene, but also conventional fillers, such as carbon black, for comparison. The experimental results obtained by Mao demonstrated that the tensile strength of a composite filled with $2.0 \%$ vol. of GO was twice as high as that of rubber composite filled with $20.0 \%$ vol. of carbon black ${ }^{7}$.

According to Ponnamma, the mechanical behavior of elastomer nanocomposites depends on several factors, such as filler dispersion, the degree of interfacial adhesion between elastomers and filler, and the crosslinking density of the composite 5 . The observed absence of strength improvement (tensile strength, stress at 100, 200, and $300 \%$ elongation) of XNBR composites with layered aluminosilicates may be explained by structural studies. The WAXS results for XNBR Bentonite did not reveal an increased interlayer distance (when bentonite in bulk was compared with bentonite in composite), which suggests poor dispersion and an insufficient amount of bentonite added ( $2 \mathrm{phr})$, as indicated before. In the case of XNBR graphene oxide, despite the WAXS curve showing exfoliation of graphene oxide layers (the absence of WAXS peaks), tensile strength was not improved in comparison with the reference sample of XNBR without nanofillers. This situation might be elucidated by XRD studies, as according to literature data X-ray diffractograms of composites with graphene and silicone rubber with graphene reveal a peak shift from $2 \mathrm{q} \approx 25^{\circ}$ for graphene to $2 \mathrm{q} \approx 12^{\circ}$ for silicone rubber with graphene $e^{5}$. The peak shift confirms nanofiller exfoliation and proves the usefulness of the method.

Thus, the observed low tensile strength levels result from XNBR crosslinking with sulfur alone as well as from inadequate nanofiller dispersion in the rubber matrix.

\section{The effect of nanofiller type on the barrier properties of materials}

The addition of carbon nanofillers (graphene flakes or graphene oxide) or an aluminosilicate nanofiller (modified bentonite) to the XNBR did not affect the barrier properties of the cured compounds. The breakthrough time for XNBR composites without nanofiller and containing $2 \mathrm{phr}$ of nanofiller was very long and similar to the reference sample (480 min). This indicates very good barrier properties of XNBR composites against mineral oil, which corresponds to the highest performance level of protection - class 6 .

Furthermore, it was determined whether the thermodynamic affinity of the studied rubber-chemical substance systems affected the barrier properties of the polymer materials. Literature data concerning the solubility parameters for XNBR and mineral oil (and thus the difference between them $\left|d_{\text {rubber }}-d_{\text {solvent }}\right|$ ) were compared with experimentally obtained breakthough times. The difference between those parameters for XNBR $\left(\delta=19.70 \mathrm{MPa}^{0.5}\right)^{27}$ and mineral oil $(\delta=15.55$ $\left.\mathrm{MPa}^{0.5}\right)^{28}$ amounted to $4.15 \mathrm{MPa}^{0.5}$, which, according to Hildebrand's theory of regular solutions ${ }^{13}$ was about twice as high as $2.4 \mathrm{MPa}^{0.5}$, suggesting negligible solubility. In the studied system, as expected, the high differences in solubility parameters led to very long breakthrough times (more than $480 \mathrm{~min}$, the maximum investigated time) irrespective of the nanofiller added. 
Also Lara ${ }^{29}$ applied a generalized solubility parameter, as well as its constituent components (dispersion component, polar component, and hydrogen bond component) for predicting the resistance of elastomeric materials to permeation by chemicals (mostly solvents). Similarly to Hansen, Lara proposed the application of the RED number for evaluating barrier properties. The solubility of a polymer-solvent system may be presented in a diagram as a spherical characteristic with the polymer solubility parameter located at the center of the sphere. The radius of the sphere indicates the maximum difference in the solubility parameters of the components of the system in which dissolution is to take place. Good solvents are found inside the sphere, with poor solvents outside it.

\section{The effect of nanofiller type on the swelling properties of materials}

The XNBR composite without a filler (XNBR No filler) is characterized by minimally higher swelling in hexane $(0.21 \mathrm{~mL} / \mathrm{mL})$ than XNBR composites with nanofillers $(0.16-0.17 \mathrm{~mL} / \mathrm{mL})$ (Table 5). This means that the reference sample is slightly less densely crosslinked than the nanofiller-containing composites. Given that lower crosslinking density leads to greater deformability of chains in the rubber matrix ${ }^{17}$, the "XNBR No filler" composite should exhibit different mechanical parameters. However, this prediction was confirmed only for tensile strength at break (Fig. 3), while in the case of abrasion resistance all composites with nanofillers performed worse than "XNBR No filler."

Swelling is an important parameter influencing rubber properties $^{\mathbf{3 0}}$. It should be noted that crosslinking density increases with decreased swelling, leading to better mechanical properties of composites. This trend is in harmony with tensile strength and torque increment, which is further evidence that the nanofillers used herein may play a role not only as reinforcing fillers but also as curative agents for functionalized elastomers, such as $\mathrm{XNBR}^{26}$. In the presented case, swelling levels did not change sufficiently to enhance mechanical properties.

Table 5. Swelling properties of XNBR materials

\begin{tabular}{|l|c|c|}
\hline Material & $\begin{array}{c}\text { Volume swelling } \\
\mathrm{Q}_{\mathrm{v}} \\
\text { in hexane } \\
{[\mathrm{mL} / \mathrm{mL}]}\end{array}$ & $\begin{array}{c}\text { Elasticity constants } \\
\text { under standard } \\
\text { conditions }\left[\mathrm{kG} / \mathrm{cm}^{2}\right]\end{array}$ \\
\hline XNBR No filler & 0.21 & $\begin{array}{l}2 \mathrm{C}_{1}=1.72 \\
2 \mathrm{C}_{2}=2.82\end{array}$ \\
\hline $\begin{array}{l}\text { XNBR } \\
\text { Graphene }\end{array}$ & 0.16 & Not tested \\
\hline XNBR GO & 0.17 & Not tested \\
\hline $\begin{array}{l}\text { XNBR } \\
\text { Bentonite }\end{array}$ & 0.16 & Not tested \\
\hline
\end{tabular}

This is important in that the sulfur cross-links arising in the XNBR matrix were too few to impart favorable mechanical properties. While the addition of nanofillers to the XNBR blend increased the number of cross-links (crosslinking density), that effect was slight, possibly due to the weak interactions between the filler particles, the rubber matrix, and the crosslinking substance.

Therefore, the method of XNBR crosslinking was changed and a new method was developed involving carbon and aluminosilicate fillers to obtain composites with barrier and mechanical properties suitable for materials used in personal protective equipment. The novel solution is the subject matter of further study and a patent application. Given the obtained results, XNBR crosslinking was modified using a hybrid sulfur and metal oxide system in the presence of an ultra-accelerator ${ }^{31}$. Studies of the new system will the subject matter of an upcoming publication.

\section{CONCLUSIONS}

Carbon nanofillers (graphene flakes or graphene oxide) added in the amount of $2 \mathrm{phr}$ to XNBR crosslinked with sulfur in the presence of accelerator did not change the barrier properties of the composites. Results indicated very good barrier properties of composites against mineral oil, corresponding to the highest protection performance level (> $480 \mathrm{~min}$ ). Similar results were obtained for XNBR composites containing aluminosilicate (bentonite).

Wide-angle X-ray scattering (WAXS) examination of the composites showed a smaller interlayer distance for materials containing graphene and bentonite, indicating agglomeration of nanofiller particles, which was deemed an adverse phenomenon, leading to reduced strength parameters. AFM images revealed that graphene oxide flakes in XNBR GO are distributed irregularly and that bentonite particles in XNBR Bentonite are agglomerated, forming larger structures. Problems with dispersion may explain why the mechanical parameters of the materials were not improved. The ATR spectra of the XNBR composite shows the existence of main absorption peaks for the XNBR compounds.

The addition of a carbon nanofiller (graphene flakes or graphene oxide) or an aluminosilicate nanofiller to the XNBR blend did not improve the mechanical properties of the vulcanizates. The highest tensile strength at break was observed for XNBR Bentonite (6.35 MPa). The type of nanofiller added to the XNBR blend in the amount of 2 phr did not significantly affect this parameter. In contrast, the abrasion resistance of composites was greatly reduced, irrespective of nanofiller type, from 8000 cycles for composite XNBR no filler to 500 cycles for composite XNBR GO.

It was observed that the process of graphene addition to XNBR blend presents certain difficulties warranting further research in this area. Therefore, we developed a novel method of XNBR crosslinking with the addition of carbon and aluminosilicate nanofillers for materials with protective mechanical and barrier properties, which is the subject of a pending patent application.

\section{ACKNOWLEDGEMENTS}

The authors thank Technical University in Rzeszów, Poland for providing bentonite.

The authors thank Institute of Electronic Materials Technology in Warsaw, Poland for providing graphene flakes and graphene oxide.

The present publication is based on the results of Phase III of the National Program "Safety and working conditions improvement" funded in the years 2014-2016 in the area of research and development work by the Ministry of Science and Higher Education / The National Centre for Research and Development. 
The Program's coordinator is the Central Institute for Labour Protection-National Research Institute.

\section{LITERATURE CITED}

1. Gołębiewski, J. (2004). Polymer nanocomposites. Structure, methods of preparation and properties. Przem. Chem. 83 (1), 15-20.

2. Alexandre, M. \& Dubois, P. (2000). Polymer-layered silicate nanocomposites: Preparation, properties and uses of a new class of materials. Mater. Sci. Eng. R. Rep. 28(1-2), 1-63. DOI: 10.1016/S0927-796X(00)00012-7.

3. Sadasivuni, K.K., Ponnamma, D., Thomas, S. \& Grohens, Y. (2014). Evolution from graphite to graphene elastomer composites. Prog. Polym. Sci. 39(4), 749-780. DOI: 10.1016/j. progpolymsci.2013.08.003.

4. Stephen, R., Ranganathaiah, C., Varghese, S., Joseph, K. \& Thomas, S. (2006). Gas transport through nano and micro composites of natural rubber (NR) and their blends with carboxylated styrene butadiene rubber (XSBR) latex membranes. Polymer 47, 858-870. DOI: 10.1016/j.polymer.2005.12.020.

5. Ponnamma, D., Maria, H.J., Chandra, A.K. \& Thomas, S.(2013). Rubber nanocomposites: latest trends and concepts. In book: Advances in Elastomers II Composites and Nanocomposites, Chapter: Rubber Nanocomposites: Latest Trends and Concepts, Publisher: Springer, Editors: P. M. Visakh, Sabu Thomas, Arup K. Chandra, Aji. P. Mathew, 69-107. DOI: 10.1007/978-3-642-20928-4_3.

6. Yaragalla, S., Sindam, B., Abraham, J., Raju, K.J., Kalarikkal, N. \& Thomas, S. (2015). Fabrication of Graphite-Graphene- Ionic liquid Modified Carbon nanotubes filled Natural rubber thin Films for Microwave and Energy storage Applications. J. Polym. Research, 22(7), 1-10. DOI:10.1007/ s10965-015-0776-5.

7. Mao, Y., Wen, S., Chen, Y., Zhang, F., Panine, P., Chan, T.W., Zhang, L., Liang, Y. \& Liu, L. (2013). High performance graphene oxide based rubber composites. Scientific Reports 3(2508). DOI:10.1038/srep02508.

8. Debelak, B. \& Lafdi, K. (2007, May). Use of exfoliated graphite filler to enhance polymer physical properties [Full text]. Carbon. 45(9), 1727-1734. Retrieved April 10, 2014, from Science Direct: www.sciencedirect.com. DOI: 10.1016/j. carbon.2007.05.010.

9. Jang, B.Z. \& Zhamu, A. (2008). Processing of nanographene platelets (NGPs) and NGP nanocomposites: a review. $J$. Mater. Sci. 43(15), 5092-51013. DOI: 10.1007/s10853-008-2755-2.

10. Kang, H., Zuo, K., Wanga, Z., Zhang, L., Liu, L. \& Guo, B. (2014, February). Using a green method to develop graphene oxide/elastomers nanocomposites with combination of high barrier and mechanical performance [Full Text]. Compos. Sci. Technol. 92(2014), 1-8. Retrieved September 10, 2017, from Science Direct: www.sciencedirect.com. DOI: 10.1016/j. compscitech. 2013.12.004.

11. Wang, J., Jia, H., Tang, Y., JI, D., Sun, Y. \& Gong, X. (2013). Enhancements of the mechanical properties and thermal conductivity of carboxylated acrylonitrile butadiene rubber with the addition of graphene oxide. J. Mater. Sci. 48(4), 1571-1577. DOİ:10.1007/s10853-012-6913-1.

12. Barton, A.F.M. (1975). Solubility parameters. Chem. Rev. 75(6), 751-753.

13. Hansen, C.M. (2004). Aspects of solubility, surfaces and diffusion in polymers. Prog. Org. Coat. 51(1), 55-66. DOI: https://doi.org/10.1016/j.porgcoat.2004.05.002.

14. Krzemińska, S., Irzmańska, E., Rzymski, W., Borkowska, U., Malesa, M. \& Piłaciński, W. (2013). Polish Patent No. 219209 B1. Warsaw: Patent Office of the Republic of Poland.

15. Przybyszewska, M. \& Zaborski, M. (2012). Polish Patent No. 210461. Warsaw: Patent Office of the Republic of Poland.
16. Przepiórkowska, A. \& Prochoń, M. (2013). Polish Patent No. 213411 B1. Warsaw: Patent Office of the Republic of Poland.

17. Krzemińska, S., Rzymski, W.M., Malesa, M., Borkowska, U. \& Oleksy, M. (2016). Gloves against mineral oils and mechanical hazards. Int. J. Occup. Saf. Ergo. 22(3), 350-359. DOI: $10.1080 / 10803548.2015 .1136111$.

18. Irzmańska, E. \& Dyńska-Kukulska, K. (2012). Permeation of mineral oils through protective glove materials in view of literature data and authors' own studies. Rev. Anal. Chem. 31(2), 113-122. DOI: 10.1515/REVAC.2011.121.

19. Krzemińska, S. \& Rzymski, W.M. (2011). Barrier properties of hydrogenated acrylonitrile-butadiene rubber composites containing modified layered aluminosilicates. Mater. Sci-Poland. 29(4), 285-291. DOI: 10.2478/s13536-011-0046-0.

20. Mooney, M.J. (1940). The Thermodynamics of a Strained Elastomer. I. General Analysis. J. Appl. Phys. 11(9), 582-92.

21. Rivlin, R.S. (1947). Torsion of a rubber cylinde. J. Appl. Phys. 18, 444-449.

22. Ju, H.M., Huh, S.H., Choi, S.H. \& Lee, H.L. (2014). Structures of thermally and chemically reduced graphene. Mater. Lett. 64(3), 357-360. DOI: 10.1016/j.matlet.2009.11.016.

23. Alanyalioğlu, M., Segura, J.J., Oró-solè, J. \& CasañPastor, N. (2012). The synthesis of graphene sheets with controlled thickness and order using surfactant-assisted electrochemical processes. Carbon. 50(1), 142-152. DOI: 10.1016/j. carbon.2011.07.064.

24. Aina, Z.N. \& Azura, A.R. (2011). Effect of different types of filler and filler loadings on the properties of carboxylated acrylonitrile-butadiene rubber latex films. J. Appl. Polymer Sci. 119(5), 2815-2823. DOI: 10.1002/app.32984.

25. George, S.C., Rajan, R., Aprem, A.S., Thomas, S. \& Kim, S.S. (2016). The fabrication and properties of natural rubber-clay nanocomposites. Polymer Testing, 51, 165-173. DOİ: doi.org/10.1016/j.polymertesting.2016.03.010.

26. Laskowska, A., Zaborski, M., Boiteux, G., Gain, O., Marzec, A. \& Maniukiewicz, W. (2014). Ionic elastomers based on carboxylated nitrile rubber (XNBR) and magnesium aluminum layered double hydroxide (hydrotalcite). eXPRESS Polymer Letters 8(6), 374-386. DOI: 10.3144/expresspolymlett.2014.42

27. Satyanarayana, M.S, Bhowmick, A.K. \& Kumar, K.D. (2016). Preferentially fixing nanoclays in the phases of incompatible carboxylated nitrile rubber (XNBR)-natural rubber (NR) blend using thermodynamic approach and its effect on physico mechanical properties. Polymer 99, 21-43. DOI: http:// dx.doi.org/10.1016/j.polymer.2016.06.063.

28. Wypych, G. (2004). Handbook of plasticizers. Chem Tec Publishing. 167.

29. Lara, J., Zimmermann, F., Drolet, D., Hansen, C.M., Chollot, A. \& Monta, N. (2017). The Use of the Hansen Solubility Parameters in the Selection of Protective Polymeric Materials Resistant to Chemicals. Int. J. Current Research 9(03), 47860-47867. HAL Id: hal-01639526.

30. Varghese, H., Bhagawan, S.S. \& Thomas, S. (1999). Effects of blend ratio, crosslinking systems and fillers on the morphology, curing behavior, mechanical properties, and failure mode of acrylonitrile butadiene rubber and poly(ethylene-co-vinyl acetate) blends. J. Appl. Polymer Sci. 71(14), 2335-2364. DOI: 10.1002/(SICI)1097 4628(19990404)71:14<2335::AID-APP7>3.0.CO;2-5.

31. Krzemińska, S., Rzymski, W., Smejda-Krzewicka, A., Lipińska, L., Woluntarski, M. \& Oleksy, M. (2016). Patent Application No.P.419470. Warsaw: Patent Office of the Republic of Poland. 